Article

\title{
Life Cycle Assessment of an On-Road Dynamic Charging Infrastructure
}

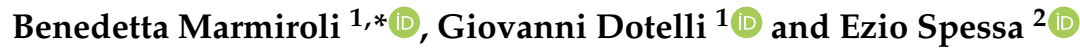 \\ 1 Mat4En2-Materials for Energy and Environment, Dipartimento di Chimica, Materiali e Ingegneria Chimica \\ "Giulio Natta", Politecnico di Milano, Piazza Leonardo da Vinci 32, 20133 Milano, Italy; \\ giovanni.dotelli@polimi.it \\ 2 Department of Energy “Galileo Ferraris", Politecnico di Torino, Corso Duca degli Abruzzi 24, 10129 Torino, \\ Italy; ezio.spessa@polito.it \\ * Correspondence: benedetta.marmiroli@polimi.it; Tel.: +39-02-2399-3232
}

Received: 11 June 2019; Accepted: 29 July 2019; Published: 1 August 2019

check for updates

\begin{abstract}
On road dynamic charging represents a possible solution for the electrification of the transport sector and eventually, for its decarbonisation. However, only a few studies have evaluated the environmental impact of this technology. A detailed life cycle assessment (LCA) of charging infrastructure is missing. This study is a life cycle assessment of the construction and maintenance of an electrified road (e-road) equipped with dynamic wireless power transfer technology (DWPT). The data from an e-road tested in a test site in Susa (Italy) have been adapted for motorway applications. The results show the relevance of wireless power transfer components compared to traditional components and materials. The wireless power transfer (WPT) component production in fact accounts for more than $70 \%$ of the impacts in the climate change category, even though it represents less than $1 \%$ weight. Maintenance is the phase with the highest impact due to the structural features of the e-road. However, there is considerable uncertainty about this value which still requires further refinement when more data from e-road monitoring are available.
\end{abstract}

Keywords: life cycle assessment; electrified road; e-road; dynamic charging; wireless power transfer; charging infrastructure

\section{Introduction}

Electric mobility has been considered intermittently since the 1990s as the upcoming solution to some of the problems of the transport sector. However, the transport sector is still mainly dominated by fossil fuels, and the widespread adoption of electric mobility still seems far from being achieved [1].

One of the main issues preventing this adoption is range anxiety on the consumer side, and the chicken and the egg problem on the availability of infrastructures. As far as the cost of ownership is concerned, there is an initial higher investment cost than internal combustion engine vehicles (ICEVs), mainly because of the price of batteries [2]. The relatively high cost of batteries, which generally limits the affordable range of an electric car to $200 \mathrm{~km}$, is also a major barrier to the electrification of heavy-duty transport, such as trucks and buses [3].

In recent years, the development of wireless power transfer (WPT) technology has been hailed as a possible solution to the range anxiety problem and to the high cost of batteries, which can pave the way towards the large-scale adoption of electric vehicles (EVs) $[4,5]$.

Further, WPT consists of the transmission of electrical energy across space, due to a time-varying electromagnetic field. It has drawn a great deal of attention for energy efficient consumer electronics and small-capacity mobile equipment use [6]. 
It may be applied to electric vehicles for both static and dynamic charging. In the static charging mode, wireless charging coil pads recharge the vehicle when it is parked or temporarily stopped.

Dynamic WPT (DWPT) charging involves a road being equipped with WPT-hereafter referred to as e-road-which supplies electricity to a vehicle while it is moving.

Inductive charging, and in particular dynamic inductive charging, could represent a real breakthrough. The key factor is the possibility of charging a battery frequently, without any effort by the user. As the battery is the most expensive component of an electric car, a smaller energy storage device could significantly lower the initial cost that people have to pay to buy an electric vehicle. It also seems suitable for consumers, since it avoids the need for inconvenient vehicle stops at charging stations [5].

The term electrified road does not imply WPT per se, but covers a wide range of charging modes while the vehicle is in motion. It can range from the classical pantograph solution, used for trolley buses in cities, to other conductive charging solutions (where the electric vehicle is physically connected to the road), and it has recently also included inductive charging, where electricity is transferred wirelessly, via an electromagnetic field (WPT technology), to vehicles.

Various technological solutions for the wireless power transfer used in electric vehicle battery chargers are currently in the research, development and demonstration phases. A brief summary of these technologies can be found in Musavi et al. [7] and in Suh et al. [6].

Even though this emerging technology has been hailed as a possible solution for the electrification of transport systems - and eventually for its decarbonisation—only a few researchers have evaluated the environmental impact of this technology, the first being Limb et al. [8], followed by Balieu et al. [9]. However, for different reasons, the impacts of infrastructure construction and maintenance were not included in these studies.

Balieu et al. [9] compared $\mathrm{CO}_{2}$ emissions and different electrified road (e-road) systems (pantographs, inductive charging and conductive rails). Their work focused on the effect of these types of charging systems on asphalt pavements and their maintenance, but it did not include electrical components when dealing with WPT solutions. Limb et al. [8] modelled the percentages of U.S.A. driving samples that could be met using WPT-enabled EV in a rollout scenario, in which all the primary and secondary roads were considered to be equipped with a DWPT infrastructure. However, the environmental impacts of the infrastructure were neglected in this analysis.

Bi et al. [10] performed a life cycle assessment (LCA) of optimised temporal and spatial e-road deployment. The impacts of the infrastructure were based on a life cycle inventory (LCI) performed in a previous work [11] and the impacts of the WPT component production were included.

The aim of this study has been to provide a detailed LCA of an e-road, in which the phases that have not yet been analysed in the literature are included. The results of this research can be the precursor of a wider analysis that includes all the aspects of electric mobility equipped with DWPT (see Figure 1).

This article provides a detailed LCI of an e-road and includes the impacts resulting from its construction and maintenance. The WPT components are described in detail, due to data gathered by Politecnico di Torino (POLITO) at the MotorOasi safe drive track in Susa (Italy) managed by Tecnositaf. To the best of the authors' knowledge, this article is the first that has included the impacts of both the WPT component production and the realisation of an e-road. 


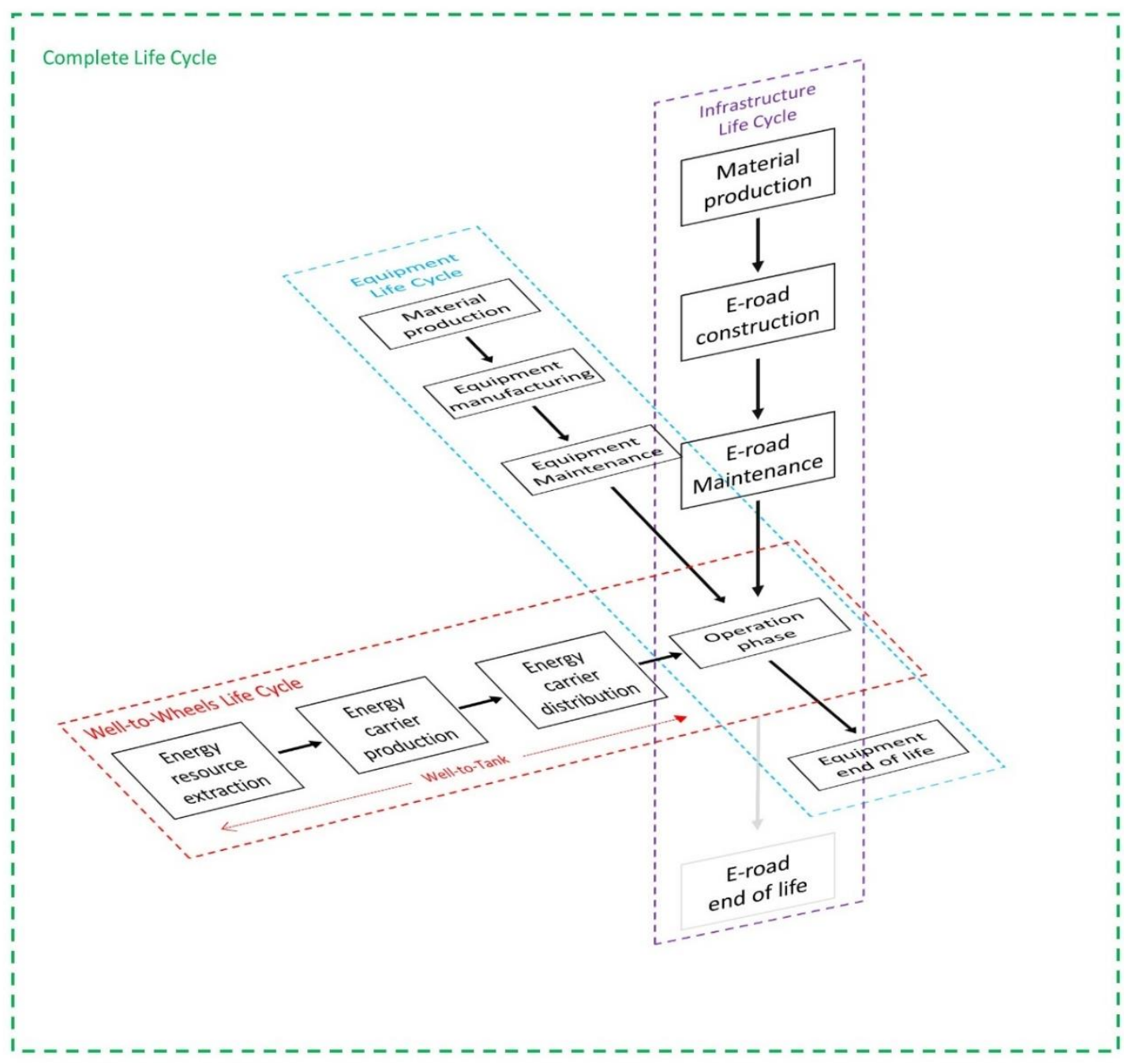

Figure 1. A schematic view of a complete life cycle assessment (LCA) of electric mobility. The impacts of infrastructure of an emerging technology should not be excluded a priori.

\section{Method}

Electric mobility is a complex theme. In order to have a complete comprehension of this phenomenon, its assessment has moved from the well-to-wheel analysis to complete LCA over the years [12]. This aspect was formalised according to the scheme of Nordelöf et al. [13]. However, an aspect was missing in their scheme-the infrastructure. In the case of an emerging technology, such as DWPT, the impact of the infrastructure cannot be neglected a priori. Thus, a holistic structure should include a third axis-the life cycle of the infrastructure. This study formalised this concept in Figure 1.

At the beginning, LCA in the transportation field focused only on a well-to-wheel analysis, since the use phase was considered the most impacting one [14], since the focus was on the $\mathrm{CO}_{2}$ emissions of conventional vehicles. As the picture frame opened up to other impact categories (resource depletion, toxicity, ...) and to other powertrains (EVs), the role of the equipment (vehicle and battery production and dismantling) came to the fore, and the analysis moved to a complete LCA, as it has been defined by Nordelöf et al. [13].

The equipment has shown an impact ranging from $25 \%$ [15] to almost $100 \%$ when fully charged from renewable energy [16] of the Greenhouse gas emissions (GHG) of the life cycle of an EV. Its share is even more relevant on such impact categories as abiotic depletion, toxicity etc. These percentages vary significantly, depending on the lifetime and mileage of the vehicle [16], on the energy mix accounted for 
when recharging the vehicle [12], and on other parameters, such as the driving patterns [15], climatic conditions, etc.

Until recently, the role of the infrastructure has often been neglected in the LCA of traditional transportation. When infrastructure is compared with the use phase, its role usually appears to be negligible, because of the high exploitation of the roads and the predominance of the use phase.

Infrastructures are usually analyzed independently from the rest of the transportation system, and their impacts are eclipsed by the use phase, if it is included. Araùjo et al., in their LCA of roads [17] included emissions from the vehicle use phase and found that the GHG emissions of vehicles are 1000 times higher than those of the construction of the road. Similar results were found by Carlson et al. [18] for energy use.

The first LCAs of roads only included the construction phase [19-21], but the relevance of maintenance operations soon became clear. Anthonissen et al. highlighted that the durability of an asphalt pavement is a significant parameter in the calculation of the environmental impact of roads [22]. The role played by maintenance has been highlighted in various studies [23-25]. Its impact is still mainly due to material production [26,27]. According to Wayman et al. [25], asphalt production accounts for $45-95 \%$ of the environmental impact over the lifetime of roads. Similar results on the predominance of material extraction and production were also found by Giani et al. [24], and by Gschösser et al. [23].

As far as electric mobility is concerned, infrastructure also has to include charging infrastructure. Hawkins et al., in their model designed to harmonize the LCA of EVs, suggested the inclusion of infrastructure in the analysis [16]. However, very few LCAs have actually taken infrastructure into consideration. Among these, the studies by Nansai et al. [28], Zhang et al. [29] and Traut et al. [30] should be mentioned. Nansai et al. analyzed the installation of charging infrastructure in different regions in Japan, and found that the $\mathrm{CO}_{2}$ emissions, due to the recharging infrastructure, accounted for $16 \%$ of the total emissions in an electric vehicle's life cycle [28]. Traut et al. evaluated two different charging scenarios (an at home charger and an at home plus at workplace charger) and they determined the optimal allocation of workplace charging infrastructures. They found that the impact of the infrastructure is less than 3\%, as can be seen in their figures [30]. Zhang et al. assessed the environmental impact of different charging systems, expressed in terms of $\mathrm{kWh}$ of delivered electricity.

In the case of e-roads, the charging infrastructure and the roads are merged into a single system, whose role in the system level LCA of electric mobility still has to be fully investigated. The LCAs of e-roads are reported in Table 1. It follows the same structure as Figure 1 in order to show which aspects were considered by each author.

Table 1. The papers that have conducted LCAs of dynamic wireless power transfer technology (DWPT) solutions.

\begin{tabular}{cccc}
\hline Paper & Well-to-Wheel & Equipment & Infrastructure \\
\hline Balieu et al. [9] & - & - & $\begin{array}{c}\text { Construction and maintenance } \\
\text { (WPT components excluded) }\end{array}$ \\
\hline Bi et al. [10] & $\begin{array}{c}\text { Electricity to recharge } \\
\text { included (at a fleet level) }\end{array}$ & & $\begin{array}{c}\text { WPT components (off board battery chargers) } \\
\text { (installation and maintenance excluded) }\end{array}$ \\
\hline Bi et al. [11] & $\begin{array}{c}\text { Electricity to recharge } \\
\text { included (at a bus level) }\end{array}$ & $\begin{array}{c}\text { Reduced } \\
\text { battery size }\end{array}$ & $\begin{array}{c}\text { WPT components (off board battery chargers) } \\
\text { (installation and maintenance excluded) }\end{array}$ \\
\hline
\end{tabular}

The focus of the present paper has been to provide a full LCA of an e-road, in which the construction and maintenance of the road have been included as well as the WPT components. The results of this analysis are expected to be used in a future system level LCA analysis. Due to the collaboration with the test site in Susa (Italy), this study is able to provide primary data for the WPT components and construction technique. 
There are a variety of relationships between the three axes in Figure 1 and they can also have an effect from an environmental point of view. Each axis not only contributes to the system level LCA, but also significantly affects the performance of the other ones. The emissions due to the energy carrier directly affect the performance of the vehicle use phase, but, on the other hand, the EVs at a system level can also affect the performance of the grid. Many studies have dealt with the role played by the EV fleet in integrating renewable energy sources (RES) and in absorbing an intermittent supply due to a more flexible demand [12] and the option of smart charging [31].

The roads directly affect the performance of a vehicle through the rolling resistance [32]. This aspect was analyzed by Araújo et al. [17] who found that surface course materials have a great influence on rolling resistance and therefore affect the performance of a vehicle during the use phase. According to these authors, the reductions that can be obtained by applying a surface course with a lower rolling resistance may be substantially higher than those of the construction phase.

On the other hand, vehicles play an important role in determining the performance and in particular, the maintenance operations of a road. Chen et al. [33] highlighted the effect of autonomous driving $(\mathrm{AD})$ and the consequent reduced wheel wander in the accelerated cracking of the road, and in the increased frequency of maintenance operations. Balieu et al. [9] analysed similar aspects pertaining to the increased load in the central lane due to the specificity of dynamic charging. As transmission efficiency is related directly to the alignment of the vehicle and the centre of the lane, it affects the maintenance operations.

An e-road infrastructure can have various effects on electric mobility as a system. It can:

- Foster the adoption of EVs;

- Lead to a change in the demand for electricity for EVs (moving from nighttime to daytime, and from dislocated charging spots in urban areas to congested motorways);

- Change consumer behavior in that there is no need for stops or a reduced frequency of stops to recharge the vehicle

- Lead to changes in the technological solutions. The adoption of this type of charging requires autonomous driving (AD), since AD significantly reduces wheel wander, and dynamic charging has demonstrated a close relationship between coil alignment and charging efficiency [34].

However, a complete LCA of an e-road has to be performed as the first step. This study focused on the impact of the realisation of an e-road and the impact of its maintenance, as a part of a larger work which will involve a complete system level LCA.

\subsection{E-Road}

The present study analysed the impact of a motorway that has been upgraded to include DWPT technology. The e-road design and the WPT layout are the result of a joint effort of different partners from the European project "feasibility analysis and development of on-road charging solutions for future electric vehicles (FABRIC)" [35]. The design of the e-road depends on the application it is intended for.

E-roads lend themselves to many applications, including private transport, freight trucks and public transport. Buses were among the first pilots to use WPT $[11,36]$. The application of inductive charging to urban buses results in several advantages, including fixed routes [37], the easily obtainable standardisation of the vehicles and the involvement of municipalities [34].

The fixed route and the time spent at stations while loading and unloading passengers are exploited to have enough charge to cover the whole bus route [37]. The particular nature of this type of transport allows buses to mainly be recharged using WPT systems and the buses to be provided with a buffer battery [37].

The transition to WPT for private transport is more complex, but the potential $\mathrm{CO}_{2}$ savings are relevant [10]. This type of infrastructure will first be deployed along high-density motorways. The introduction of WPT to motorways will act as a range extender for electric vehicles going from 
one city to another, thus allowing time savings to be achieved, since the recharging occurs while the vehicle is in motion.

The scenarios developed by FABRIC considered the trans-European transport network (TEN-T) infrastructure as a first deployment, where the DWPT infrastructure have dedicated $25 \mathrm{~km}$ long lanes (in both directions) for the dynamic charging of light and heavy electric-vehicles along the most crowded motorways between two locations approximately 400 to $600 \mathrm{~km}$ apart. The lane is not reserved for WPT vehicles.

The layout of a suitable e-road for such a scenario was developed as part of a collaboration between the partners of the FABRIC project. The WPT solution was developed by POLITO.

POLITO developed the charge while driving (CWD) solution, which is based on the dynamic wireless resonant inductive coupling principle [38]. The details on the layout are presented in [38-41]. Hereafter, a simple, brief description is given to help understand the system and the subsequent LCI.

The primary coils collect power from a low-voltage, three-phase, connection point and the road-side control system converts the AC voltage to DC and then to a $600 \mathrm{~V} 100 \mathrm{kHz}$ rectangular waveform in order to transfer the power, through the air gap, to a secondary coil.

The POLITO solution at the test site consists of 2 branches of 25 coils individually fed by DC/HF converters. Each coil has a DC/HF converter and the distribution is at $600 \mathrm{~V}$ DC. The feeder can be connected in parallel to the same cable (see Figure 2).

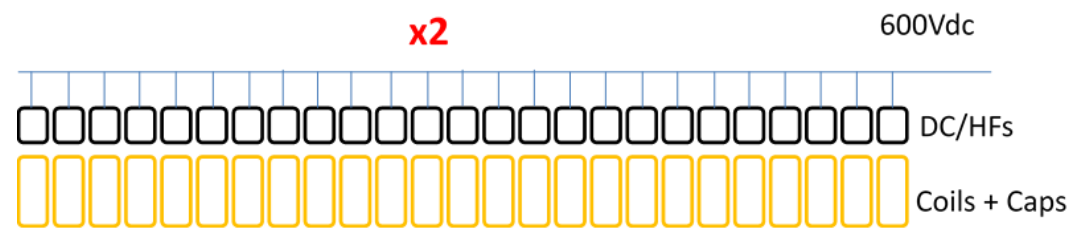

Figure 2. The layout of the Politecnico di Torino (POLITO) system at the test site.

In addition, a super capacitor solution is provided to balance the possible load variations.

The power electronics can operate at any frequency over the $20-200 \mathrm{kHz}$ range, although it is essential that the primary and secondary circuits operate at the same frequency.

The CWD system operates as a constant secondary current, which means that the power control can be done at the secondary side without any additional controller. This means that it is also easier to transfer power back to the network. However, no power will be sent back to the grid in the developed solution.

The power transfer rate is $20 \mathrm{~kW}$. The secondary voltage will be able to span from 0 to $400 \mathrm{~V}$, that is, for a full rate power transfer from 300 to $400 \mathrm{~V}$. The primary input voltage will be $600-700 \mathrm{~V}$ DC.

The current solutions are connected to three-phase $400 \mathrm{~V}$ AC substation feeder points. However, the current solutions are primarily experimental and are mainly used in controlled environments, where the installation is only used by a small number of vehicles. However, as the solutions are installed on a large scale, other forms of connections should be considered as a result of the foreseen higher demand levels, stepping up from $\mathrm{kW}$ to an MW range. A similar approach that has been used for railways is proposed, where the connection point will be at medium voltage (MV) or even high voltage $(\mathrm{HV})$ feeders. This approach would also isolate the in-road power transfer infrastructure from the domestic supply. A possible adaptation of the POLITO solution for motorway applications is reported in Figure 3.

In real world applications, all the charging coils will be embedded in the road surface at a depth of 6-7 cm, while the power electronics and control equipment will be placed in plastic manholes at the sides of the track.

The rectangular coils used in the POLITO solution consist of 10 concentric windings, and external dimensions of $1.6 \mathrm{~m} \times 0.6 \mathrm{~m}$, while the diameter of the coils is $0.4 \mathrm{~cm}$. The tail of the loops, which have to be connected to the power control equipment, will be placed in a PVC pipe. The power electronics and control equipment will be placed in the manholes at the sides of the track. The PE will be connected 
to a shelter (1 shelter every $50 \mathrm{PE}, 25$ per side), which will receive power from an AC/DC converter, which in turn supplies power to the charging area through a $2 \times 16 \mathrm{~mm}$ FG7R/FG7OR 0.6/1 kV cable. The main power and data transmission networks will be connected to a grid infrastructure by means of a cable pipe that connects all the manholes and run beside the charging lane. Each substation will be equipped with an MV/LV transformer and an AC/DC converter to convey a direct low voltage current (650-700 V DC) to the segments.

A list of the POLITO WPT components, sorted by function, may be observed in Table 3 .

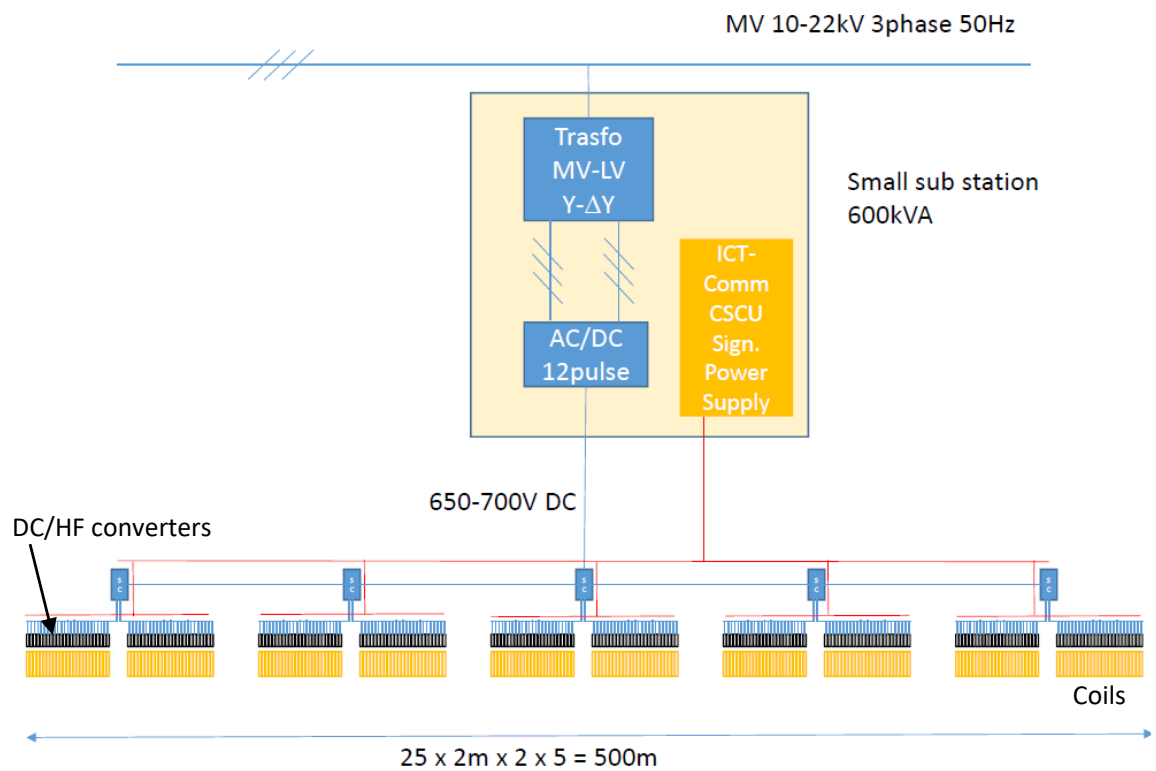

Figure 3. The adaptation of the POLITO solution for motorway applications.

\section{Road Geometry and Construction}

The optimal configuration for the POLITO technology requires the installation of the coils $4 \mathrm{~cm}$ beneath the road surface. However, there is some allowance in depth of the positioning, thus the coils may be placed in the bitumen layer, even though the overhead wear layer is more than $4 \mathrm{~cm}(6 \mathrm{~cm}$ in the analysed case, see Figure 4).

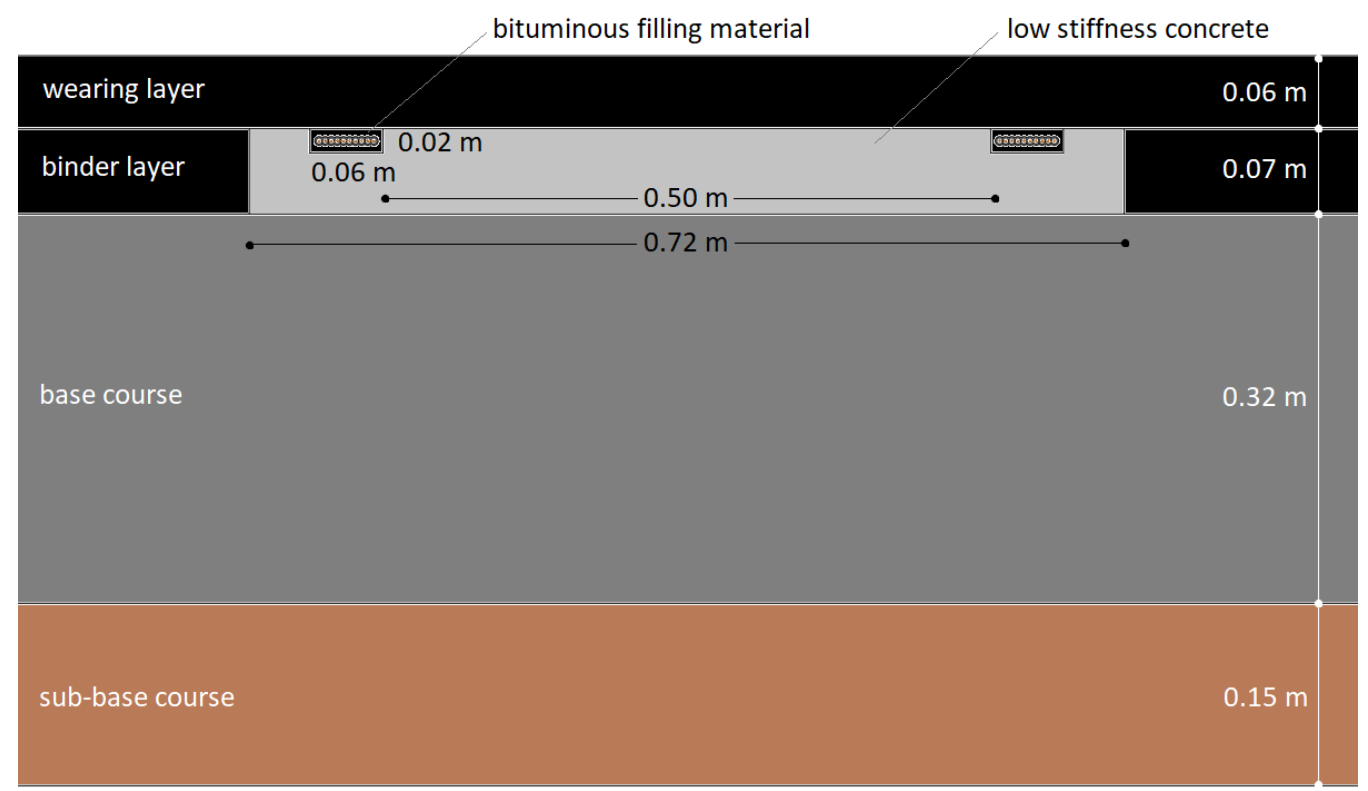

Figure 4. The section of the POLITO solution adapted for motorway applications. 
In order to install this system along a motorway, it is necessary to dismantle both the wear and binder layers, and then to place the coils, previously coated with bitumen, into a low stiffness concrete and cover the whole system with asphalt [42]. A section of the actual design of the adaptation of the POLITO solution for motorway implementation is reported in Figure 4.

\subsection{Goal and Scope Definition}

The aim of this study has been to evaluate the impact of the construction and maintenance of an e-road, in order to pave the way towards a complete analysis of an electric mobility system equipped with DWPT charging technology. To this aim, the structure of the e-road designed in the framework of the FABRIC project has been analysed. The considered road is a motorway, where one lane has been upgraded to include DWPT equipment.

\subsubsection{Functional Unit}

The functional unit is $1 \mathrm{~km}$ of the lane on the right of a traditional motorway-which is representative of an average European motorway-upgraded to an e-road, which is able to provide $50 \mathrm{~kW}$ power to vehicles and $100 \mathrm{~kW}$ to trucks. The time horizon is 20 years, at the end of which the e-road could be demolished or remain in situ and serve as a support for a subsequent pavement structure.

Pavements are not easily defined through one, or even a few functional units. This is due to the fact that the pavement structure (i.e., the type, thickness and properties of the materials) is influenced to a great extent by the characteristics of the traffic, the environmental conditions, the design life and other project-specific details. The variability of these elements creates a situation where two pavements of equal length may have fundamentally different characteristics $[43,44]$.

The definition of the functional unit becomes even more complex in the case of an e-road, since it provides another function to the road, that is, it extends the range of the vehicles. However, this range extension depends on several factors, such as the users' behaviour, driving style, the use of accessories, etc. The energy transferred to a vehicle as it covers the total length of the e-road at $100 \mathrm{~km} / \mathrm{h}$ perfectly aligned with the coils could be chosen as a proxy of the extended range. Moreover, the number of rechargeable vehicles on each segment is limited and depends on the configuration of the road. Therefore, the functional unit could be defined as the extended range-vehicle when different e-road solutions are compared.

This study has defined a declared unit as $1 \mathrm{~km}$ of e-road, while the function of the e-road can be defined when the system level LCA is performed.

According to Santero et al., it is difficult to define a single functional unit that is suitable for each and every road. The important aspect is that the functional unit should address a standardised set of characteristics that accurately describe the pavement structure and its material properties, the performance standards for the pavement, and the relevant exogenous variables, such as climate [43].

Thus, in this study, a declared unit (1 km of e-road) has been chosen which provides a series of performances (time duration, power provided, ... ).

\subsubsection{System Boundary}

The definition of the system boundaries plays an important role in the LCA of roads [43].

In the present study, the system boundaries were defined on the basis of the work of Stripple et al. [45], who summarised all the phases that should be included when performing an LCA of a road. In this study, this scheme has been adapted to an e-road.

Stripple et al. divided the system boundaries into three phases: construction, maintenance and operation. According to their definition, the final disposal of a road is normally included in the maintenance of the road, and some of the materials are reused. However, most roads have no final end. Instead, they are generally reconstructed or replaced by a new road while the old road remains in operation [45]. 
In this study, the construction phase of the e-road includes the removal of the wear and binder layers of the existing road and the application of WPT equipment as well as the following deposition and compaction of asphalt. The following are included in the construction phase:

- Production of the raw materials;

- Transport of the raw materials to the construction site;

- Transport of the on-site equipment to the construction site;

- Equipment use (fuels);

- Construction of the e-road;

- Production of the charging (and any other electrical devices);

- Transport of the charging unit to the road construction site;

- Installation of the charging devices.

The construction method is described in Section 3. The construction of the e-road involves the refurbishment of a traditional road, and the construction operations only involve asphalt layers, and the base and sub-base layers remain unchanged. Thus, the base and sub-base layers have been excluded from the analysis.

E-roads also present particular features during the maintenance phase. The alignment of the vehicle with the coils embedded in the road is a fundamental aspect when it comes to charging efficiency. In fact, for recharging reasons, the maximum allowed misalignment for power transfer is approximately $20 \mathrm{~cm}$ [46]. The presence of a discontinuity in the asphalt layer and the fixed trajectory the vehicle has to follow in order to maximise charging can lead to a need for additional maintenance, compared to a traditional road.

In order to understand the effects of WPT technologies on the maintenance of pavements, Ceravolo et al. [47] performed a finite element simulation. Moreover, the maintenance operations, due to the replacement of WPT components, were included in the analysis.

As far as the maintenance phase is concerned, the following activities have been included in the present analysis:

- Production of the raw materials required for the maintenance;

- Transport of the raw materials to the road site;

- Transport of the on-site equipment;

- $\quad$ Equipment use (fuels);

- Maintenance of the charging unit and WPT components.

The winter maintenance procedures, such as sand and salt gritting and snow clearance, depend on the weather conditions and have been excluded from the analysis, since their relevance is negligible [9].

The impacts attributable to the end-of-life phase of the pavement depend on the ultimate fates of the road surface and its constituent materials, which are notoriously difficult to determine a priori. At the end of its service life, a pavement can meet one of three fates: It may (1) be demolished and landfilled; (2) be demolished and recycled; or (3) remain in situ and serve as a support for a subsequent pavement structure [43]. As infrastructures are rarely demolished completely or disposed of after the end of their life [48], this phase has not been considered in this analysis.

\subsubsection{Data Quality}

The data on the layout of DWPT and e-road construction have been collected at the test site. As these data describe the test site solution, which has not been optimised for real-world implementation, they were adapted following an interview with experts. The data on maintenance operations were derived from the work of Ceravolo et al., who applied a computational recursive approach to predict the lifetime of a road and the damage to the charging unit (CU). The data regarding components, material production and transportation were derived from the EcoInvent database, version 3.3, (cut-off approach). 


\subsubsection{Impact Categories}

Considering that this study has been aimed at evaluating a representative e-road, rather than a specific one, it was preferred to consider established global impact categories, i.e., climate change, instead of local, site-dependent impacts. In this analysis, the climate change has been evaluated using the "baseline model of $100 \mathrm{a}$ " by IPCC (IPCC 2013 GWP 100a V1.03). The results are expressed in kilograms of $\mathrm{CO}_{2}$-equivalents per declared unit. The conversion of substances emitted into the atmosphere to a reference unit was made through the global warming potential (GWP100) characterisation factor.

Energy consumption is particularly important for road LCAs [44]. Bitumen has a relevant feedstock energy, and the way it should be accounted for is a matter of debate. The cumulative energy demand (CED) [49] is assessed in order to ease energy comparisons. It was chosen here since energy consumption is the most popular metric used in the evaluation of existing road surfaces in LCAs $[43,44]$. This method represents a measure (expressed in megajoules) of direct and indirect energy use over the entire life cycle of a product. It accounts for energy produced from non-renewable sources (fossil, nuclear and non-renewable biomasses) and renewable sources (wind, solar, geothermic, hydro and renewable biomasses).

Oil dependency is an important issue for the electrification of the transport sector. For this strategical reason, the consumption of fossil fuels, both as a source of energy and embedded in construction materials (such as asphalt and bituminous emulsion) was taken into account. To evaluate this aspect, the "Abiotic depletion-Fossil Fuels" impact category was calculated, using the April 2013 updated version (v. 4.2) of the CML baseline method [50].

\section{Life Cycle Inventory}

\subsection{Material Production}

The amounts of pavement materials and WPT components per km were derived from the e-road design. The amount required to build $1 \mathrm{~km}$ of e-road is reported in Tables 2 and 3.

The production of the materials required for the upgrading of the road into an e-road were calculated using data available in the literature and in the EcoInvent datasets. When not directly available, the dimensions and weights of the DWPT components were estimated. Each component is presented in more detail hereafter.

\subsubsection{Asphalt}

An asphalt pavement is a blend of mineral aggregates and bitumen. The percentages vary according to the use and production techniques. The bitumen content is approximately $4-6 \%$, and the rest is made up of gravel, sand and/or mineral filler and possibly reclaimed asphalt pavement (RAP).

The environmental impacts of asphalt production depend to a great extent on the bitumen content, on the RAP content [24] and on the technology used to produce it (hot mix asphalt, warm mix asphalt or cold mix asphalt) [51].

The environmental performance of asphalt pavements is very sensitive to transportation distances, hence the comparisons that can be made are very site specific [48]. The transportation of the asphalt to the construction site varies according to the contingency, but it is suggested to keep this value as low as possible. The distance between the construction and production sites should not be longer than 80-100 km, especially for hot mix asphalt (HMA), because bitumen has to be kept at a high temperature to be workable during paving operations. [52].

Table 2. The materials per km of e-road.

\begin{tabular}{ccc}
\hline Materials & Use & Quantity Per km \\
\hline Asphalt & Wear and binder layers & $992,394 \mathrm{~kg}$ \\
Bituminous emulsion & Bond between layers & $2190 \mathrm{~kg}$ \\
Concrete & Coil housings & $113,760 \mathrm{~kg}$ \\
\hline
\end{tabular}


Table 3. Wireless power transfer (WPT) components per km of e-road.

\begin{tabular}{|c|c|c|c|}
\hline Components & Quantity Per km & Weight & Unit \\
\hline \multicolumn{4}{|l|}{ Power Supply } \\
\hline Main Transformer & 10 units & 340 & $\mathrm{~kg} /$ unit \\
\hline Power metering & 10 units & & \\
\hline Protection and shunting circuits & 10 units & & \\
\hline AC/DC Converter & 10 units & 40 & $\mathrm{~kg} / \mathrm{unit}$ \\
\hline \multicolumn{4}{|l|}{ Distribution Shelter } \\
\hline Shelter & 10 units & 10.2 & $\mathrm{~kg} /$ unit \\
\hline Super-capacitors box & 10 units & 0.06 & $\mathrm{~kg} /$ unit \\
\hline Control Power Supply & 10 units & 1.20 & $\mathrm{~kg} /$ unit \\
\hline PE box management unit & 10 units & 0.00994 & $\mathrm{~m}^{2}$ \\
\hline CSCU & 10 units & 0.75 & $\mathrm{~kg} / \mathrm{unit}$ \\
\hline \multicolumn{4}{|l|}{ Coil, Cabling and Capacitors } \\
\hline Coil & 500 coils & 7.1 & $\mathrm{~kg} /$ unit \\
\hline Connectors & 500 units & 0.009 & $\mathrm{~kg} /$ unit \\
\hline Capacitors & 500 units & 50.5 & g/unit \\
\hline \multicolumn{4}{|l|}{ Power Electronics (DC/HF) } \\
\hline Power Electronics board & 500 units & 0.00994 & $\mathrm{~m}^{2} /$ unit \\
\hline Active Bridge & 500 units & & \\
\hline Housing & 500 units & 1.0260 & $\mathrm{~kg} /$ unit \\
\hline Connectors & 500 units & 0.009 & $\mathrm{~kg} / \mathrm{unit}$ \\
\hline \multicolumn{4}{|l|}{ Distribution lines } \\
\hline Manholes & 250 units & 0.0162 & $\mathrm{~m}^{3} /$ unit \\
\hline Distribution Pipes & $250 \mathrm{~m}$ & 0.161 & $\mathrm{~kg} / \mathrm{m}$ \\
\hline 650VDC Distribution cables with connectors & $200 \mathrm{~m}$ & 1.04 & $\mathrm{~kg} / \mathrm{m}$ \\
\hline Signal communication cables and connectors & $200 \mathrm{~m}$ & 1.04 & $\mathrm{~kg} / \mathrm{m}$ \\
\hline Signal power supply cables and connectors & $200 \mathrm{~m}$ & 1.04 & $\mathrm{~kg} / \mathrm{m}$ \\
\hline
\end{tabular}

The choice of the mixture for an asphalt road surface is closely related to the purpose of the road, to site specific aspects, etc. The production of a traditional asphalt mix requires that the aggregates are completely dry before they can be bound with bitumen (which is hydrophobic). This requires heating the aggregates up to $160^{\circ} \mathrm{C}$. Warm mix asphalt (WMA) is the name that is given to a variety of technologies that allow asphalt mixtures to be produced at lower temperatures. According to the European Asphalt Pavement Association (EAPA), WMA is generally produced over a temperature range of $100{ }^{\circ} \mathrm{C}$ to $140{ }^{\circ} \mathrm{C}$, while the half-warm mix asphalt (HWMA) is fabricated between $70{ }^{\circ} \mathrm{C}$ and $100^{\circ} \mathrm{C}$ [53]. The standard hot mix asphalt (HMA) is instead produced at approximately $160^{\circ} \mathrm{C}$. The cold mix asphalt has recently gained attention, since it is prepared at ambient temperatures.

In order to model asphalt production, a suitable mixture for the wear and binder layers was used. The weight percentages of the different components of the mixture are reported in Table 4 [24]. The extraction of these raw materials was modelled using the EcoInvent database, version 3.3.

Table 4. Asphalt composition [24].

\begin{tabular}{cccccc}
\hline Materials & Sand 0/3 & Gravel 3/6 & Gravel 6/12 & Filler & Bitumen \\
\hline Percentage & $16.90 \%$ & $36.60 \%$ & $35.70 \%$ & $5.70 \%$ & $5.10 \%$ \\
\hline
\end{tabular}

The HMA production has been considered. The emissions and energy consumption for HMA production were derived from the study of Giani et al. [24].

The use of recycled asphalt, a possible solution that has been suggested to obtain a reduction in environmental pressure, requires a deeper investigation of this type of application. In some cases, a thicker layer is required to ensure the same performances as virgin asphalt. The thickness is an important variable in the case of an e-road, since it directly affects the charging efficiency. 


\subsubsection{Bituminous Emulsion}

Bituminous emulsion is required to bind overlapping layers. Its use ensures a longer life of the e-road structure. It is composed of $45 \%$ water and $55 \%$ bitumen [24]. No reliable information regarding the production process has been found in literature, thus it was modelled as the sum of the production of the compounds and a generic blending process. The amount of the bituminous emulsion layer was set at a typical value of $0.6 \mathrm{~kg} / \mathrm{m}^{2}$ [24].

\subsubsection{Concrete}

The coils are embedded in a low stiffness concrete box covered with bitumen. The amount of concrete required for the construction of the pre-cast boxes is deduced from their geometry.

The production of low stiffness concrete was modelled using the EcoInvent Concrete, normal $\{$ RoW $\}$ | unreinforced concrete production, with cement CEM II/A | Alloc Rec, U dataset (amount expressed in $\mathrm{m}^{3}$; concrete density: $2370 \mathrm{~kg} / \mathrm{m}^{3}$ ).

\subsubsection{WPT Components}

The EcoInvent database has been used to account for the production of the WPT components. However, a suitable dataset was not available for every component. A specific dataset was modelled for the missing components, either by creating an ex-novo dataset or by modifying an existing one.

\subsection{Transport}

The environmental performance of roads is very sensitive to transportation distances, hence the comparisons that can be made are very site specific [48]. Since the road analysed herein is a fictitious e-road representative of the average European situation, practicable distances were considered in order to establish the role played by this phase.

The consumption associated with haulage in each process is a function of the transported volume, the lorry capacities and the distance from the construction site. The methodology used to calculate the consumption involves the following steps:

- Calculation of the weight of the materials (aggregates, machinery, etc.) that have to be transported to the plant or to the yard;

- Definition of suitable distances from the plants to the construction sites considered representative of an average European situation;

- Definition of the type of truck used to transport each material/component.

Transportation should consider: the construction materials transported from the plant to the construction site; the WPT components from the manufacturers to the plant; on site equipment and asphalt removed from the wear and binder layers and transported from the construction site to the plant, where it is recycled. The considered transport vehicles and covered distances are shown in Table 5.

Table 5. Transport of the materials and equipment to and from the construction site.

\begin{tabular}{cccc}
\hline Freight & Weight & Mileage & Vehicle Type \\
\hline Asphalt & $992 \mathrm{t}$ & $50 \mathrm{~km}$ & Truck 16-32 metric ton \\
Bituminous emulsion & $2 \mathrm{t}$ & $50 \mathrm{~km}$ & Truck 16-32 metric ton \\
WPT components & $10 \mathrm{t}$ & $100 \mathrm{~km}$ & Lorry 3.5-7.5 metric ton \\
Equipment & $62 \mathrm{t}$ & $50 \mathrm{~km}$ & Truck 16-32 metric ton \\
\hline
\end{tabular}

An average distance of $50 \mathrm{~km}$ was assumed between the construction site and the production plant for common construction materials. As transportation also has a significant effect on the costs, construction companies already optimise this aspect. Transportation must be kept below $100 \mathrm{~km}$, especially in the case of asphalt, due to the importance of keeping it warm enough to be workable. 
The asphalt and machinery were hypothesised to leave from the construction plants; the EcoInvent “Transport, freight, lorry 16-32 metric ton, EURO6 \{GLO\} | market for | Alloc Rec, U” dataset was used for the transportation.

A longer distance was considered for the WPT components: $100 \mathrm{~km}$. The WPT components were hypothesised to be delivered with smaller commercial vehicles, thus their transportation was accounted for using the EcoInvent “Transport, freight, lorry 3.5-7.5 metric ton, EURO6 \{GLO\} | market for | Alloc Rec, U" dataset.

\subsection{Construction}

There are three main construction methods for the installation of a dynamic wireless power transfer (DWPT) system: trench-based construction; full lane construction and full lane prefabricated construction. Trench-based construction consists in creating a trench in an existing motorway, installing the system, then backfilling and laying an asphalt surface layer. This method is regarded as the quickest and cheapest option, but it can cause reflective cracking on the surface. Full lane construction consists in removing the full bound layer from the lane, installing the units and cables and then surfacing with asphalt. A third option consists in replacing the upper layer of a traditional road with a full lane-width prefabricated section containing the entire system, and a possible finishing with asphalt surfacing. Trench construction is the quickest installation option and the one with the lowest initial cost. It would only require one lane closure, and relatively few vehicle movements would be required, as the excavation and fill volumes are low. However, it requires two longitudinal joints in the centre of the lane and therefore higher future maintenance and whole life costs are likely. On the other hand, full lane construction only requires a single longitudinal joint [54,55], and the whole life costs are therefore likely to be lower than trench construction. Even though it requires 2 lanes of traffic management and relatively high vehicle movements, this aspect may be mitigated, if planned along with regular maintenance operations of the pavement. The prefabricated option is the one with the highest initial cost, and there are some concerns about the disruption caused by the transport of the system to the site [54]. Full lane construction could be one of the most feasible methods, for structural and economic reasons and it is therefore the one that has been considered in the analysis. A list of the operations that have to be considered for the full lane construction method is reported hereafter:

- Removal of the wear and binder layers, e.g., using a jack hammer and cold planer (milling machines). This can be similar to the normal road surface rehabilitation procedure that involves the replacement of the surface layer every few years.

- Installation of E-Road solutions: WPT components (charging unit and the associated connection pipework) delivered to the site in precast form.

- Covering with asphalt and the application of a tack coat to ensure adequate bonding between the layers.

The production of the pavement materials and the use of onsite equipment were considered to model these phases. The amount of pavement materials was obtained from the e-road design reported in Figure 4, while the fuel consumption of the machinery was obtained from datasheets available on the manufacturers' websites.

A machine with a milling width of $2 \mathrm{~m}$ and a weight of $28.9 \mathrm{t}$ was chosen, with a construction fuel consumption of $52 \mathrm{~L} / \mathrm{h}$. The time required for the removal of the surface layers is a function of the milling depth, and it was obtained from the manufacturer's datasheet. Thus, the fuel consumption required to mill $1 \mathrm{~km}$ of road to a milling depth of $13 \mathrm{~cm}$ was derived as the milling speed and the hourly consumption multiplied by two, since the full width of the lane $(3.65 \mathrm{~m})$ requires the machine to pass twice.

The emissions due to diesel burned in the milling machine were obtained using the EcoInvent "Diesel, burned in agricultural machinery GLO" dataset. The wear from machinery use was disregarded. 
Before the deposition of the coils and the new layers, the use of a sweeping machine is required to remove debris. In order to model the use of the sweeping machine, the performances of a commercially available machine, with a weight of 1.8 tonnes, were analysed. A machine with a nominal power of $205 \mathrm{~kW}$ and with a sweeping width of 4 metres on average consumes $15 \mathrm{~L} / \mathrm{h}$, and the sweeping speed is $2.5 \mathrm{~km} / \mathrm{h}$. The fuel necessary to clean one kilometre was calculated assuming a diesel density of $0.835 \mathrm{~kg} / \mathrm{L}$.

The coils may be deposited in two different ways: an in-situ method and a pre-cast solution. The pre-cast solution implies that the coils arrive at the site already embedded in their low-stiffness concrete boxes. Using a pre-cast system in this situation might be preferable as there would be no need to wait for the concrete to set compared to the case where the coils are inserted in situ. This means that the asphalt layer could be laid immediately, thus reducing construction times. The use of extendible trailers with a crane for the installation of pre-cast concrete tram tracks was considered for this solution.

The technical data of a commercially available trailer crane was used to model the use of a trailer.

Once the boxes containing the coils have been installed, they are again covered with binder and wear layers. The repaving procedure involves the following steps:

- A paver distributes asphalt over the lane, ensuring that the full width of the lane is covered.

- A roller then compacts the asphalt to make the thickness and compaction uniform. More than one passage is usually required to obtain the desired compactness.

- The application of an emulsion linking layer over the binder: An adequate joining coat is necessary between the road layers to ensure a longer life of the e-road structure. This connection may be done with a bituminous emulsion.

In order to obtain the fuel consumption for the reconstruction of the lane after the WPT module has been embedded, a paver with an operating width of $3.75 \mathrm{~m}$ was considered (power $130 \mathrm{~kW}$, weight $19 \mathrm{t}$ ). The consumption of diesel depends on the quantity of asphalt that has to be paved, and on the thickness of the layers. The speed of the paving machine for a $6 \mathrm{~cm}$ thick layer is $1028.8 \mathrm{~m}^{2} / \mathrm{h}$ and the hourly fuel consumption is $23.2 \mathrm{~L} / \mathrm{h}$. A paving machine with a $1.4 \mathrm{~m}$ operating width and a weight of $6.4 \mathrm{t}$ was selected for the binder layer. Its clearance width of $1.4 \mathrm{~m}$ allows the two lateral areas to be covered, without damaging the coils. A paving speed of $30 \mathrm{~m} / \mathrm{min}$ and a nominal power of $55.4 \mathrm{~kW}$ were considered. As the hourly consumptions were not available, they were derived from the consumption of the larger paving machine, assuming a linear relationship between power and consumption.

A roller machine with a roller width of $2 \mathrm{~m}$ was chosen for the compaction of the wear layer. Another roller with an operating width of $1.5 \mathrm{~m}$ was considered for the binder layer. The fuel consumptions of the aforementioned machinery are reported in Table 6.

The larger roller has to repeat the rolling twice, for both the binder and the wear layers, in order to cover the full width of the lane. The slimmer roller was selected for the binder, as it has to pass along the lane twice, without pressing the coils. For precautionary reasons, the same fuel consumption was assumed for each passage, even though the consumption decreases as the compaction of the layers grows.

The quantities can be set at the typical value of $0.6 \mathrm{~kg} / \mathrm{m}^{2}$ for the bituminous emulsion layer [24].

An emulsion spraying machine is used to spray bituminous emulsion, which acts as a binder between the wear and binder layers. The considered machine had a power of $265 \mathrm{~kW}$ and an operation width of $4 \mathrm{~m}$ (see Table 6). The operating speed was $20 \mathrm{~km} / \mathrm{h}$ and the hourly fuel consumption was $8.3 \mathrm{~L} / \mathrm{h}$. 
Table 6. The technical data of the considered machines.

\begin{tabular}{|c|c|c|c|}
\hline Machinery & Operation & Characteristics & Fuel Consumption \\
\hline $\begin{array}{l}\text { Milling } \\
\text { machine }\end{array}$ & $\begin{array}{l}\text { Removal of the wear and } \\
\text { binder layers }\end{array}$ & $\begin{array}{c}\text { Milling width } 2 \text { m; Weight } 28.9 \text { t. } \\
\text { Two passages }\end{array}$ & $111.33 \mathrm{~kg} / \mathrm{km}$ \\
\hline $\begin{array}{l}\text { Sweeping } \\
\text { machine }\end{array}$ & Debris removal & $\begin{array}{l}\text { Weight } 1.8 \mathrm{t} \text {, nominal power } 205 \\
\mathrm{~kW} \text {, sweeping width } 4 \text { m average } \\
\text { consumption } 15 \mathrm{~L} / \mathrm{h} \text {, sweeping } \\
\text { speed } 2.5 \mathrm{~km} / \mathrm{h}\end{array}$ & $5.01 \mathrm{~kg} / \mathrm{km}$ \\
\hline Paver & $\begin{array}{l}\text { Wear asphalt deposition } \\
\text { Binder asphalt } \\
\text { deposition }\end{array}$ & $\begin{array}{l}\text { operating width of } 3.75 \mathrm{~m} \text {, power } \\
130 \mathrm{~kW} \text { weight } 19 \mathrm{t}, 1028.8 \mathrm{~m}^{2} / \mathrm{h} \\
\text { hourly, fuel consumption } 23.2 \mathrm{~L} / \mathrm{h}\end{array}$ & $69 \mathrm{~kg} / \mathrm{km} 29.4 \mathrm{~kg} / \mathrm{km}$ \\
\hline Roller & $\begin{array}{l}\text { Compacting binder } \\
\text { Compacting wear layer }\end{array}$ & $\begin{array}{c}\text { Weight } 12.5 \mathrm{t} \text {; Roller width } 2 \mathrm{~m} \text {; } \\
\text { Nominal Power } 100 \mathrm{~kW} \text {; Speed } \\
0.27 \mathrm{~km} / \mathrm{h} \text {; Fuel consumption } 21.2 \\
\text { L/h. Passages: } 6\end{array}$ & $161 \mathrm{~kg} / \mathrm{km} 786 \mathrm{~kg} / \mathrm{km}$ \\
\hline $\begin{array}{l}\text { Emulsion } \\
\text { sprayer }\end{array}$ & $\begin{array}{l}\text { Spraying of a bituminous } \\
\text { emulsion between the } \\
\text { wear and binder layers }\end{array}$ & $\begin{array}{c}265 \mathrm{~kW} \text { power, operation width } 4 \\
\text { m operating speed } 20 \mathrm{~km} / \mathrm{h} \text {. fuel } \\
\text { consumption } 8.3 \mathrm{~L} / \mathrm{h}\end{array}$ & $0.346 \mathrm{~kg} / \mathrm{km}$ \\
\hline
\end{tabular}

\subsection{Maintenance}

The maintenance phase may contribute significantly to the overall environmental impact [44]. In the case of an e-road, the introduction of the WPT system, within an existing infrastructure, could result in structural issues [56-58].

Ceravolo et al. [47] performed a long-term fatigue analysis to understand the possible structural effects of the introduction of a charging system into a road. In their paper, they presented a recursive procedure for the estimation of the lifetime of an e-road.

This model was adapted to our needs. They fixed the time horizon as 20 years and determined the frequency of the rehabilitation of the wear and binder layers in order to prevent cracking.

The obtained results require wear rehabilitation every 25 months. This leads to eight wear rehabilitations during the life time of the e-road, as one rehabilitation is substituted by the wider "wear and binder layer rehabilitation" (at least once during the lifetime of the infrastructure, the entire asphalt layer, i.e., wear and binder, must be replaced) and one is avoided due to the final disposal of the road at the end of its life.

The fatigue endurance of the concrete boxes where the coils are embedded is greater than 20 years, according to Ceravolo et al. [47], therefore no replacement of these components was considered during the lifetime of the e-road.

The emissions from equipment, material production (asphalt and bitumen) and the transportation of materials and equipment to the construction site are considered in this phase.

The activities related to wear rehabilitation are similar to those of traditional roads, although some precaution must be taken due to the presence of the WPT equipment. The activities in the central area of the lane should be conducted with machines that are able to do fine milling, so as not to damage the coils embedded in the concrete boxes, while standard machines may be used for the remaining area.

The consumptions of the equipment were calculated in a similar way as the construction process and are reported in Table 7.

A high uncertainty exists related to the duration of the components and to the frequency of the maintenance. The fatigue duration of the various components of an e-road is subject to several uncertainties and should be evaluated only after the collection of a considerable amount of real data. 
Table 7. The equipment consumptions for wear layer rehabilitation.

\begin{tabular}{|c|c|c|c|}
\hline Machinery & Operation & Characteristics & Fuel Consumption \\
\hline Milling machine & $\begin{array}{l}\text { Removal of the upper } \\
\text { part of the wear layer }\end{array}$ & $\begin{array}{l}\text { Operating width } 2 \mathrm{~m} \text {; Weight } 28.9 \mathrm{t} . \\
\text { Two passages }\end{array}$ & $55.66 \mathrm{~kg} / \mathrm{km}$ \\
\hline $\begin{array}{l}\text { Milling machine } \\
\text { (fine) }\end{array}$ & $\begin{array}{l}\text { Fine milling of the wear } \\
\text { layer closer to the coils }\end{array}$ & $\begin{array}{l}\text { Milling width; Milling depth } 1 \mathrm{~mm} \text {; Speed } \\
2.5 \mathrm{~km} / \mathrm{h} \text {; Hourly consumption } 30 \mathrm{~L} / \mathrm{h}\end{array}$ & $20.04 \mathrm{~kg} / \mathrm{km}$ \\
\hline $\begin{array}{l}\text { Emulsion sprayer } \\
\text { machine }\end{array}$ & $\begin{array}{l}\text { Bitumen emulsion } \\
\text { deposition }\end{array}$ & $\begin{array}{l}265 \mathrm{KW} \text { power; Operating width } 4 \mathrm{~m} \\
\text { operating speed } 20 \mathrm{~km} / \mathrm{h} \text {; fuel consumption } \\
8,3 \mathrm{~L} / \mathrm{h}\end{array}$ & $0.346 \mathrm{~kg} / \mathrm{km}$ \\
\hline Paver & Asphalt deposition & $\begin{array}{c}\text { Operating width of } 3.75 \mathrm{~m} \text {; power } 130 \mathrm{~kW} \text {; } \\
\text { weight } 19 \mathrm{t} \text {; Speed } 1028.8 \mathrm{~m}^{2} / \mathrm{h} \text {; Fuel } \\
\text { consumption } 23.2 \mathrm{~L} / \mathrm{h}\end{array}$ & $69 \mathrm{~kg} / \mathrm{km}$ \\
\hline Roller & Compacting wear layer & $\begin{array}{l}\text { Weight } 12.5 \mathrm{t} \text {; Roller width } 2 \mathrm{~m} \text {; Nominal } \\
\text { Power } 100 \mathrm{~kW} \text {; Speed } 0.27 \mathrm{~km} / \mathrm{h} \text {; Fuel } \\
\text { consumption } 21.2 \mathrm{~L} / \mathrm{h} \text { Passages: } 6\end{array}$ & $767 \mathrm{~kg} / \mathrm{km}$ \\
\hline
\end{tabular}

The products required for the rehabilitation were derived from the road stratigraphy and have been reported in Table 8 .

Table 8. The materials required for wear layer rehabilitation.

\begin{tabular}{ccc}
\hline Materials & Use & Quantity \\
\hline Asphalt & Wear layers & $512,406 \mathrm{~kg} / \mathrm{km}$ \\
Bituminous emulsion & Bonding between layers & $2190 \mathrm{~kg} / \mathrm{km}$ \\
\hline
\end{tabular}

The transportation of the equipment and materials to the construction site was considered using the same procedure as that used for the construction phase.

When the wear and binder layer rehabilitation takes place, the lateral areas and the central one are milled separately: A $1.5 \mathrm{~m}$ wide milling machine, with a milling depth of $13 \mathrm{~cm}$, is used for the two sides. The fuel consumption required to mill $1 \mathrm{~km}$ of road at a milling depth of $13 \mathrm{~cm}$ was derived from the milling speed (using speed-depth diagrams supplied by the manufacturer) and the hourly consumption was multiplied by two (because of the two lateral areas).

The same procedure as the wear rehabilitation was adopted for the central areas.

It was assumed that the precast coils would remain in the ground for the entire operation.

In order to provide a benchmark, the life cycle of a traditional road has been considered as a reference. Since the subject of the study is the revamping of an existing t-road into an e-road, in order to make fair comparison, it has been supposed that the reference t-road at time 0 , when the e-road was built starting from a t-road, underwent a refurbishment of the wear and binder layers. Thus, only the maintenance operations have been included in the analysis, while the base and subbase remain unchanged in both of the configurations. In order to make a fair comparison, only the regular maintenance operations of the t-road have been considered for the same lifespan of the e-road (20 years). The frequency of the maintenance operations was taken from the literature. The rehabilitation of the wear layer is expected every 5 years, while rehabilitation of the wear and binder layers is expected at least once in the lifetime of the road [24].

The wear and binder layer maintenance operations have been modelled using the same machinery used for the e-road. The amount of asphalt that has to be replaced has been calculated considering the geometry of the road (the layer thicknesses are supposed to be the same as those of the e-road). 


\section{Results and Discussion}

\subsection{Contruction Phase}

The aim of a life cycle impact assessment (LCIA) is to present the potential link between the product life cycle and the environmental impacts and to quantify them. The impact categories considered in this analysis are the cumulative energy demand (CED), the AD-fossil fuel and climate change.

The results of the impact assessment of the construction phase and of the production of the materials are listed in Table 9 and Figure 5.

Table 9. The impacts of the e-road construction per functional unit, i.e., per $1 \mathrm{~km}$.

\begin{tabular}{cccc}
\hline Phase & CED [MJ/km] & AD-Fossil Fuels [MJ/km] & Climate Change [kg CO $\left.\mathbf{C O}_{\mathbf{2}}-\mathbf{e q} / \mathbf{k m}\right]$ \\
\hline Material production & $4,752,868$ & $4,313,584$ & 155,114 \\
Transport & 144,597 & 143,051 & 9040 \\
Construction & 64,227 & 63,941 & 4162 \\
\hline
\end{tabular}

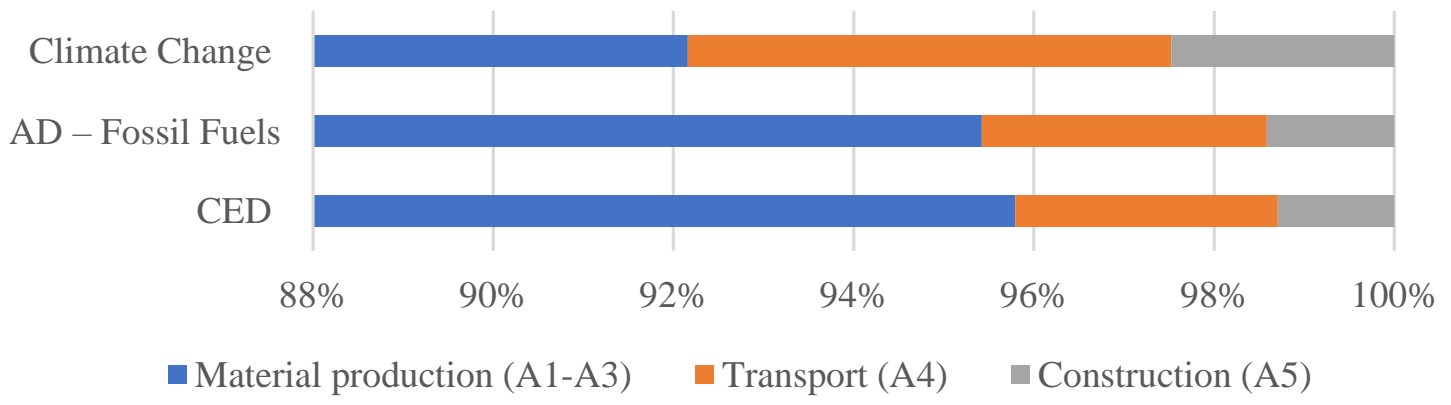

Figure 5. The percentages of the different phases on the overall impact.

If the materials used to build the e-road are examined more closely, the role of the WPT components emerges (see Table 10).

Table 10. The materials used for the construction phase.

\begin{tabular}{ccccc}
\hline \multirow{2}{*}{ Materials } & $\begin{array}{c}\text { Amount } \\
{[\mathbf{k g} / \mathbf{k m}]}\end{array}$ & CED [MJ/km] & $\begin{array}{c}\text { AD-Fossil Fuels } \\
{[\mathbf{M J} / \mathbf{k m}]}\end{array}$ & $\begin{array}{c}\text { Climate Change } \\
{[\mathbf{k g ~ C O} \text {-Eq/km] }}\end{array}$ \\
\hline \multirow{2}{*}{ Asphalt } & 992,394 & $3,149,172$ & $3,002,414$ & 44,484 \\
& $89 \%$ & $66 \%$ & $70 \%$ & $29 \%$ \\
\hline \multirow{2}{*}{ Concrete } & 113,760 & 72,386 & 67,544 & 10,316 \\
& $10 \%$ & $2 \%$ & $2 \%$ & $7 \%$ \\
\hline Bituminous & 2190 & 61,226 & 59,177 & 480 \\
emulsion & $0 \%$ & $1 \%$ & $1 \%$ & $0 \%$ \\
\hline \multirow{2}{*}{ WPT components } & 10,687 & $1,470,084$ & $1,184,449$ & 99,834 \\
& $1 \%$ & $31 \%$ & $27 \%$ & $64 \%$ \\
\hline Total & $1,119,031$ & $4,752,868$ & $4,313,584$ & 155,114 \\
\hline
\end{tabular}

Even though the WPT components represent less than $1 \%$ by weight, they play a significant role on the impacts (see Figure 6). 


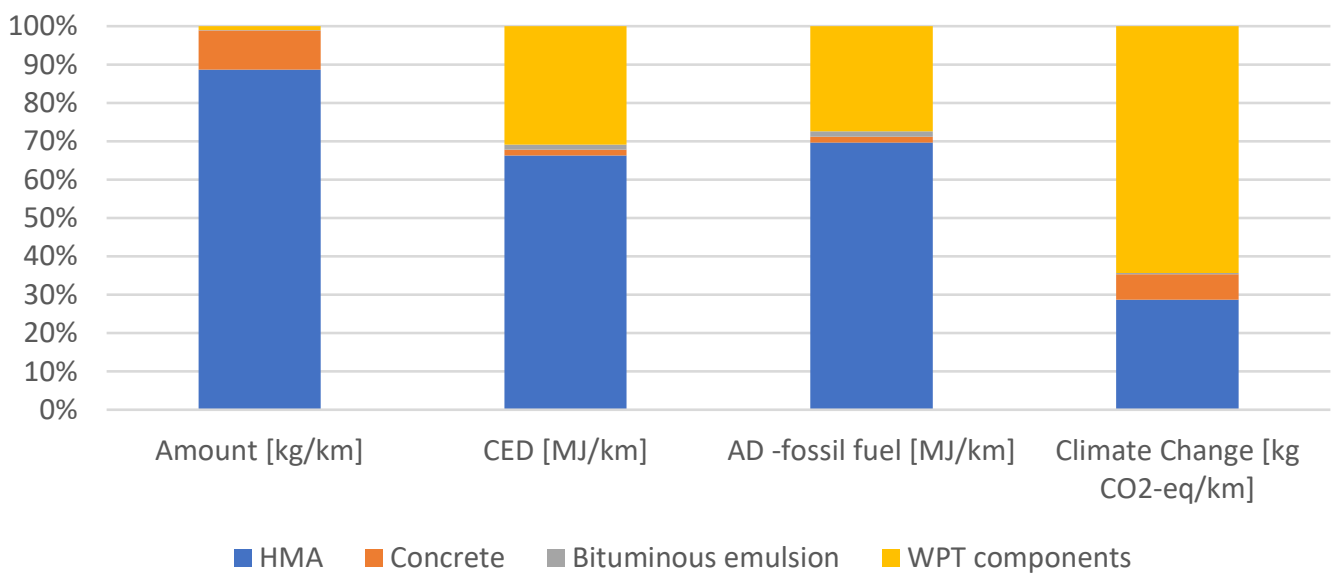

Figure 6. The e-road materials and components: Impacts and weights per $\mathrm{km}$.

Impacts of the sub-phases are reported more in detail in Table 11.

Table 11. The impacts of the e-road construction per functional unit, i.e., per $1 \mathrm{~km}$.

\begin{tabular}{lccc}
\hline Sub-Phase & $\begin{array}{c}\text { CED } \\
{[\mathbf{M J} / \mathbf{k m}]}\end{array}$ & $\begin{array}{c}\text { AD-Fossil } \\
\text { Fuels }[\mathbf{M J} / \mathbf{k m}]\end{array}$ & $\begin{array}{c}\text { Climate Change } \\
{\left[\mathbf{k g ~ C O} \mathbf{C O}_{\mathbf{2}} \text {-Eq/km] }\right.}\end{array}$ \\
\hline Dismantling & 6534 & 6505 & 423 \\
\hline Installation and paving & 57,693 & 57,436 & 3739 \\
\hline Transport (construction materials and WPT components) & 134,406 & 132,970 & 8404 \\
\hline Transport (equipment) & 10,191 & 10,081 & 636 \\
\hline HMA production & $3,149,172$ & $3,002,414$ & 44,484 \\
\hline WPT production & $1,470,084$ & $1,184,449$ & 99,834 \\
\hline Bituminous emulsion production & 61,226 & 59,177 & 480 \\
\hline Concrete production & 72,386 & 67,544 & 10,316 \\
\hline Total & $4,961,692$ & $4,520,576$ & 168,317 \\
\hline
\end{tabular}

\subsection{Maintenance}

The impacts due to the single wear layer rehabilitation are listed in Table 12, while the impacts of the wear and binder layer rehabilitation are listed in Table 13.

Table 12. The impacts of the wear layer rehabilitation.

\begin{tabular}{lccc}
\hline Sub-Phase & CED [MJ/km] & $\begin{array}{c}\text { AD-Fossil } \\
\text { Fuels [MJ/km] }\end{array}$ & $\begin{array}{c}\text { Climate Change } \\
{\left[\mathbf{k g} \text { CO }_{2}-\text { Eq/km] }\right.}\end{array}$ \\
\hline Transport (asphalt and bituminous emulsion) & 59,130 & 58,493 & 3692 \\
\hline Wear layer dismantling & 4533 & 4513 & 294 \\
\hline Wear layer repaving-machinery & 48,078 & 47,864 & 3116 \\
\hline HMA production & $1,626,194$ & $1,550,409$ & 22,971 \\
\hline Bituminous emulsion production & 61,226 & 59,177 & 480 \\
\hline Transport (machinery) & 8261 & 8172 & 516 \\
\hline Total & $1,807,422$ & $1,728,628$ & 31,069 \\
\hline
\end{tabular}


Table 13. The impacts of the wear and binder layer rehabilitation.

\begin{tabular}{lccc}
\hline Sub-Phase & CED [MJ/km] & $\begin{array}{c}\text { AD-Fossil } \\
\text { Fuels [MJ/km] }\end{array}$ & $\begin{array}{c}\text { Climate Change } \\
{[\mathbf{k g ~ C O} \text {-Eq/km] }}\end{array}$ \\
\hline Transport (asphalt and bituminous emulsion) & 113,046 & 113,042 & 7136 \\
\hline Wear and binder layer dismantling & 7650 & 7649 & 498 \\
\hline Wear and binder layer repaving-machinery & 57,421 & 57,420 & 3738 \\
\hline HMA production & $3,003,115$ & $3,002,413$ & 44,484 \\
\hline Bituminous emulsion production & 59,178 & 59,177 & 480 \\
\hline Transports (machinery) & 10,752 & 10,752 & 679 \\
\hline Total & $3,251,162$ & $3,250,453$ & 57,014 \\
\hline
\end{tabular}

The impacts of $1 \mathrm{~km}$ of e-road are reported in Table 14 assuming eight wear layer rehabilitations during its lifetime (20 years).

Table 14. The impacts of an e-road construction and maintenance for a lifetime of 20 years.

\begin{tabular}{lccc}
\hline Phase & CED [MJ/km] & $\begin{array}{c}\text { AD-Fossil } \\
\text { Fuels [MJ/km] }\end{array}$ & $\begin{array}{c}\text { Climate Change } \\
{\left[\mathbf{k g} \mathbf{C O}_{\mathbf{2}} \text {-Eq/km] }\right.}\end{array}$ \\
\hline E-road construction & $4,961,692$ & $4,520,576$ & 168,317 \\
\hline Wear Layer Rehabilitation (every 2 years) & $14,459,377$ & $13,829,023$ & 248,551 \\
\hline Wear and Binder Layer Rehabilitation & $3,251,162$ & $3,250,453$ & 57,014 \\
\hline Total & $22,672,230$ & $21,600,052$ & 473,882 \\
\hline
\end{tabular}

The impact percentages are presented in Figure 7, divided per phase and sub-phase. The three impact categories follow the same trend. This is no surprise considering the close correlation between CED, fossil fuels and $\mathrm{CO}_{2}$ in the current production systems. The wear layer rehabilitation is the most relevant phase, because of the frequent occurrence of wear layer rehabilitations during the life cycle of an e-road. Asphalt production presents higher impacts for CED and HMA than climate change. CED and AD—fossil fuels include feedstock energy, while feedstock energy has no effect on climate change.

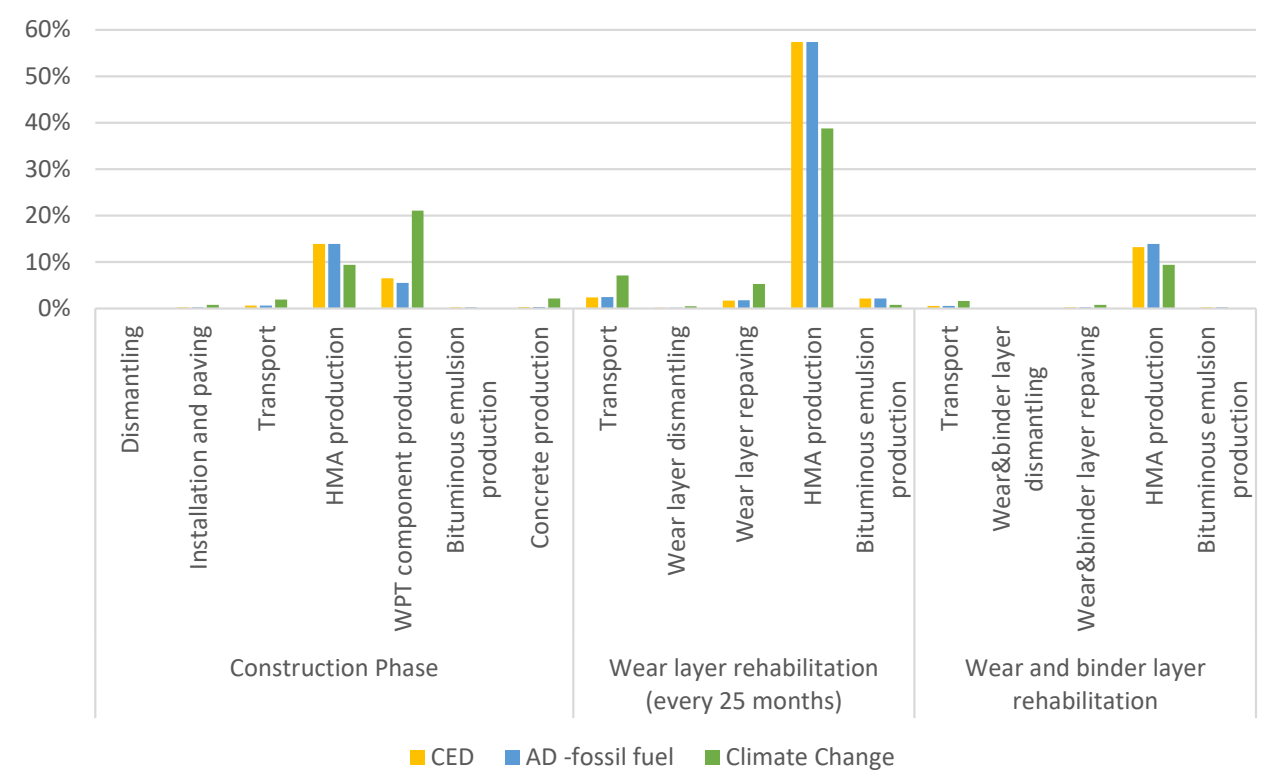

Figure 7. The e-road impacts divided per phase and sub-phase. 
According to the previously performed fatigue analysis, eight wear layer rehabilitations should be conducted during the lifetime of an e-road. However, the endurance of the wear layer is the most uncertain quantity and can vary from approximately 2 years to no more than 5 years (from 3 up to 9 rehabilitations in 20 years of the design life). The average endurance of the entire asphalt layer (e.g., binder and wear) can be set at approximately 10 years. Thus, the rehabilitation of the binder layer over 20 years of design life is generally only done once. The cumulative energy demand of the e-road is shown in Figure 8 considering the different wear rehabilitation frequencies.

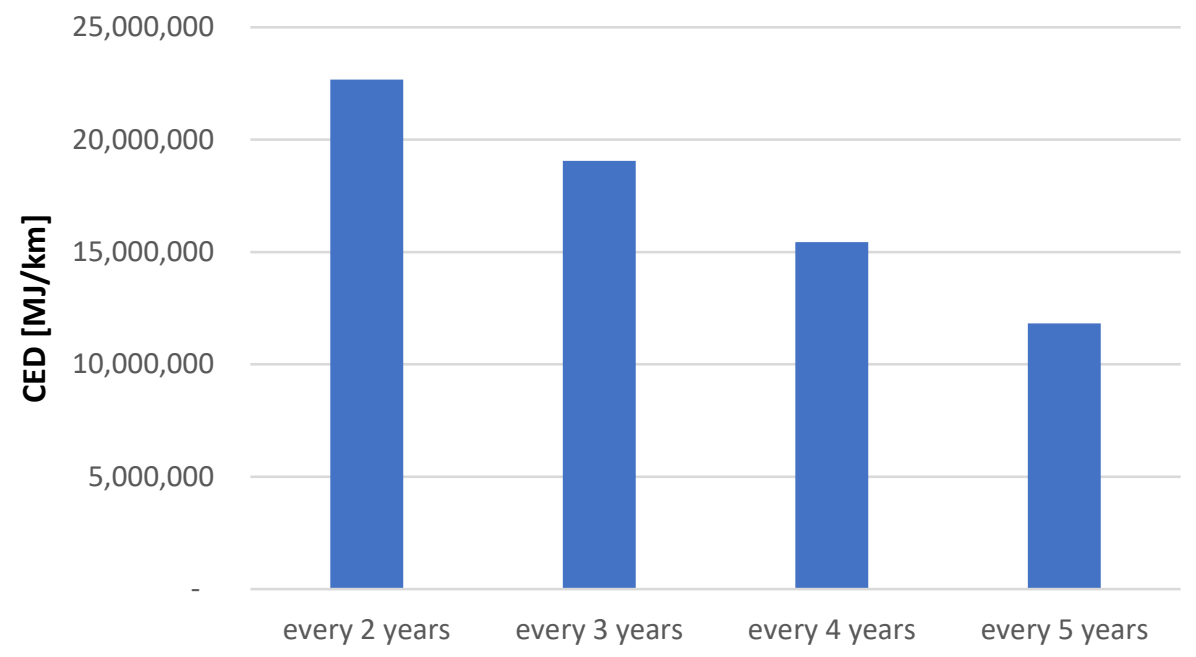

Figure 8. The cumulative energy demand of $1 \mathrm{~km}$ of e-road considering the different wear layer rehabilitation frequencies.

As can be seen from Figure 8 and Table 15, the frequency of the maintenance operation can halve the final results, thus suggesting that future work should be done to reduce the related uncertainty, and to optimise the structural and material features.

Table 15. The impacts of an e-road construction and maintenance with the different wear layer rehabilitation frequencies.

\begin{tabular}{cccc}
\hline Wear Layer Rehabilitation Frequency & CED [MJ/km] & $\begin{array}{c}\text { AD-Fossil } \\
\text { Fuels [MJ/km] }\end{array}$ & $\begin{array}{c}\text { Climate Change } \\
\text { [kg CO } \mathbf{~ - E q / k m ] ~}\end{array}$ \\
\hline Every 2 years & $22,672,230$ & $21,600,052$ & 473,882 \\
Every 3 years & $19,057,386$ & $18,142,796$ & 411,745 \\
Every 4 years & $15,442,542$ & $14,685,541$ & 349,607 \\
Every 5 years & $11,827,698$ & $11,228,285$ & 287,469 \\
\hline
\end{tabular}

The frequency of the wear layer rehabilitation is still uncertain and influences the impact assessment of an e-road to a great extent. This aspect requires refinement when more data from e-road monitoring are available.

The impacts of the e-road have been compared with those of a t-road in order to provide a reference. The obtained results refer to a traditional t-road which has undergone a wear and binder layer rehabilitation at time 0 , when the e-road was built by revamping a traditional road, as explained in Section 3. The results of this comparison are reported in Table 16.

Table 16. The impacts of an e-road construction and maintenance for a lifetime of 20 years.

\begin{tabular}{cccc}
\hline & CED [MJ/km] & AD-Fossil Fuels [MJ/km] & Climate Change [kg CO $\mathbf{2}-\mathbf{E q} / \mathbf{k m}]$ \\
\hline E-road & $22,672,230$ & $21,600,052$ & 473,882 \\
T-road & $11,814,331$ & $10,512,842$ & 227,122 \\
\hline
\end{tabular}


The results show that the e-road presents almost double the impacts of a traditional road in almost all the analysed impact categories as a result of the production and installation of the WPT components and of the more frequent maintenance operations. However, these figures should be considered simply as a reference. As mentioned in the methodological section, this impact needs to be considered from a larger perspective that also considers the effect of the infrastructure on the other three axes. In fact, compared to traditional roads, e-roads have a greater impact, but they fulfil an additional function to a $\mathrm{t}$-road, thus making the comparison unfair when it is limited to the declared unit ( $\mathrm{km}$ of $\mathrm{t}$-road/e-road).

\section{Conclusions and Recommendations}

E-roads can have an important role in fostering the adoption of electric mobility. Since transportation is a complex system, the impact of an infrastructure such as an e-road has to be included in a system level LCA which encompasses all the axes of electric mobility - the vehicle; the energy carrier and infrastructure - and their mutual interconnections, as visually represented in Figure 1. Nevertheless, a complete LCA of an e-road was still missing and the aim of the study was to perform such an analysis.

The study has involved performing an LCA of $1 \mathrm{~km}$ of e-road, equipped with DWPT technology. A detailed inventory of the WPT components was included in the analysis due to the availability of the data gathered at the test site in Susa. The construction phase was modelled according to the instructions provided by TRL and the durability of the asphalt pavement and WPT components was the result of a finite element analysis that had already been performed in the Fabric project.

The results of the LCIA show the predominance of the WPT component production in the construction phase. They account for more the $30 \%$ of the share in all the impact categories, even though they are less than $1 \%$ of the total components in weight. Maintenance is the phase with the highest impact due to the structural features of the e-road. There is high uncertainty about both the durability of pavements and WPT components in e-roads. These values require further refinement when more data from e-road monitoring are available.

A comparison with $1 \mathrm{~km}$ of a traditional road has been performed. The results show that the impacts of the e-road are almost double those of the traditional road. However, these figures should be considered simply as a reference. In fact, e-roads have a greater impact than traditional roads, but they also fulfil an additional function to a t-road, thus making a comparison unfair if it is limited to the declared unit ( $\mathrm{km}$ of t-road versus $\mathrm{km}$ of e-road). As mentioned in the methodological section, these impacts should be considered from a larger perspective that also takes into account the mutual effect of the infrastructure with the transportation system. This analysis represents a first step in the evaluation of the dynamic charging solution as a whole.

Author Contributions: B.M., G.D. and E.S. conceived the paper. B.M. collected the data for the LCI and wrote the paper. E.S. and G.D. revised the paper.

Funding: The research leading to these results received funding from the European Union's Seventh Framework Programme for research, technological development and demonstration under grant agreement no. 605405 (FABRIC).

Acknowledgments: We would like to thank all the FABRIC participants for their contributions.

Conflicts of Interest: The authors declare no conflict of interest.

\section{References}

1. Taiebat, M.; Xu, M. Synergies of four emerging technologies for accelerated adoption of electric vehicles: Shared mobility, wireless charging, vehicle-to-grid, and vehicle automation. J. Clean. Prod. 2019, 230, $794-797$. [CrossRef]

2. Vanhaverbeke, L.; Schreurs, D.; De Clerck, Q.; Messagie, M.; Van Mierlo, J. Total cost of Ownership of Electric Vehicles Incorporating Vehicle to Grid Technology. In Proceedings of the 2017 Twelfth International Conference on Ecological Vehicles and Renewable Energies (EVER), Monte Carlo, Monaco, 11-13 April 2017; pp. 1-6. 
3. Connolly, D. Economic viability of electric roads compared to oil and batteries for all forms of road transport. Energy Strat. Rev. 2017, 18, 235-249. [CrossRef]

4. Sampson, E. Wireless Technologies and the Transformation of Transport; International Transport Forum: Paris, France, 2010.

5. Ou, C.; Liang, H.; Zhuang, W. Investigating wireless charging and mobility of electric vehicles on electricity market. IEEE Trans. Ind. Electron. 2014, 62, 3123-3133. [CrossRef]

6. Suh, I.; Suh, I.; Kim, J. Electric Vehicle on-Road Dynamic Charging System with Wireless Power Transfer Technology. In Proceedings of the 2013 International Electric Machines \& Drives Conference, Chicago, IL, USA, 12-15 May 2013; pp. 234-240.

7. Musavi, F.; Edington, M.; Eberle, W. Wireless Power Transfer: A Survey of EV Battery Charging Technologies. In Proceedings of the 2012 IEEE Energy Conversion Congress and Exposition (ECCE), Raleigh, NC, USA, 15-20 September 2012; pp. 1804-1810.

8. Limb, B.; Asher, Z.; Bradley, T.; Sproul, E.; Trinko, D.; Crabb, B.; Zane, R.; Quinn, J.C. Economic Viability and Environmental Impact of In-Motion Wireless Power Transfer. IEEE Trans. Transp. Electrif. 2019, 5, 135-146. [CrossRef]

9. Balieu, R.; Chen, F.; Kringos, N.R. Life cycle sustainability assessment of electrified road systems. Road Mater. Pavement Des. 2019, 20, S19-S33. [CrossRef]

10. Bi, Z.; Keoleian, G.; Lin, Z.; Moore, M.; Chen, K.; Song, L.; Zhao, Z. Life cycle assessment and tempo-spatial optimization of deploying dynamic wireless charging technology for electric cars. Transp. Res. Part C Emerg. Technol. 2019, 100, 53-67. [CrossRef]

11. Bi, Z.; Song, L.; De Kleine, R.; Mi, C.; Keoleian, G. Plug-in vs. wireless charging: Life cycle energy and greenhouse gas emissions for an electric bus system. Appl. Energy 2015, 146, 11-19. [CrossRef]

12. Marmiroli, B.; Messagie, M.; Dotelli, G.; Van Mierlo, J. Electricity generation in LCA of electric vehicles: A review. Appl. Sci 2018, 8, 1384. [CrossRef]

13. Nordelöf, A.; Messagie, M.; Tillman, A.; Söderman, M.L.; Van Mierlo, J. Environmental impacts of hybrid, plug-in hybrid, and battery electric vehicles-What can we learn from life cycle assessment? Int. J. Life Cycle Assess. 2014, 19, 1866-1890. [CrossRef]

14. Eriksson, E.; Blinge, M.; Lövgren, G. Life cycle assessment of the road transport sector. Sci Total Environ. 1996, 189, 69-76. [CrossRef]

15. Ma, H.; Balthasar, F.; Tait, N.; Riera Palou, X.; Harrison, A. A new comparison between the life cycle greenhouse gas emissions of battery electric vehicles and internal combustion vehicles. Energy Policy 2012, 44, 160-173. [CrossRef]

16. Hawkins, T.R.; Gausen, O.M.; Strømman, A.H. Environmental impacts of hybrid and electric vehicles-a review. Int. J. Life Cycle Assess. 2012, 17, 997-1014. [CrossRef]

17. Araújo, J.P.C.; Oliveira, J.R.M.; Silva,H.M.R.D. The importance of the use phase on the LCA of environmentally friendly solutions for asphalt road pavements. Transp. Res. Part D Transp. Environ. 2014, 32, 97-110. [CrossRef]

18. Carlson, J.; Roh, M.H.; Chang, M.C.; Crum, C.P. Recent advances in the understanding of the pathogenesis of serous carcinoma: The concept of low-and high-grade disease and the role of the fallopian tube. Diagn. Histopathol. 2008, 14, 352-365. [CrossRef]

19. Ventura, A.; Monéron, P.; Jullien, A. Environmental impact of a binding course pavement section, with asphalt recycled at varying rates: Use of life cycle methodology. Road Mater. Pavement Des. 2008, 9, 319-338. [CrossRef]

20. Leng, Z.; Al-Qadi, I. Comparative Life Cycle Assessment Between Warm SMA and Conventional SMA; Illinois Tollway: Springfield, IL, USA, 2011.

21. Nicuta, A. Life cycle assessment study for new and recycled asphalt pavements. Bul. Inst. Politeh. Sect. Constr. Arhit. 2011, 57, 81.

22. Anthonissen, J.; Braet, J. Review and environmental impact assessment of green technologies for base courses in bituminous pavements. Environ. Impact Assess. Rev. 2016, 60, 139-147. [CrossRef]

23. Gschösser, F.; Wallbaum, H.; Adey, B.T. Environmental analysis of new construction and maintenance processes of road pavements in Switzerland. Struct. Infrastruct. Eng. 2014, 10, 1-24. [CrossRef]

24. Giani, M.I.; Dotelli, G.; Brandini, N.; Zampori, L. Comparative life cycle assessment of asphalt pavements using reclaimed asphalt, warm mix technology and cold in-place recycling. Resour. Conserv. Recycl. 2015, 104, 224-238. [CrossRef] 
25. Wayman, M.; Andersson-Sköld, Y.; Bergman, R.; Huang, Y.; Parry, T.; Raaberg, J.; Enell, A. Re-road End-of-Life Strategies of Asphalt Pavements. 2012. Available online: http://re-road.fehrl.org/?m=48\&id directory $=7325$ (accessed on 31 July 2019).

26. Gulotta, T.; Mistretta, M.; Praticò, F. A life cycle scenario analysis of different pavement technologies for urban roads. Sci. Total Environ. 2019, 673, 585-593. [CrossRef]

27. Gulotta, T.M.; Mistretta, M.; Praticò, F.G. Life cycle assessment of roads: Material and process related energy savings. Model. Meas. Control. C 2018, 79, 146-147. [CrossRef]

28. Nansai, K.; Tohno, S.; Kono, M.; Kasahara, M.; Moriguchi, Y. Life-cycle analysis of charging infrastructure for electric vehicles. Appl. Energy 2001, 70, 251-265. [CrossRef]

29. Zhang, Z.; Messagie, M.; Hegazy, O.; Van Mierlo, J. The Environmental Performance of Different Power Rate's Charging Infrastructure for Electric Vehicles, a Life Cycle Perspective. In Proceedings of the 2017 IEEE Vehicle Power and Propulsion Conference (VPPC), Belfort, France, 11-14 December 2017; pp. 1-7. [CrossRef]

30. Traut, E.; Hendrickson, C.; Klampfl, E.; Liu, Y.; Michalek, J.J. Optimal design and allocation of electrified vehicles and dedicated charging infrastructure for minimum life cycle greenhouse gas emissions and cost. Energy Policy 2012, 51, 524-534. [CrossRef]

31. Egede, P.; Dettmer, T.; Herrmann, C.; Kara, S. Life Cycle Assessment of Electric Vehicles-A Framework to Consider Influencing Factors. Procedia CIRP 2015, 29, 233-238. [CrossRef]

32. Bendtsen, H. Rolling Resistance, Fuel Consumption-A Literature Review; Danish Road Directorate: Roskilde, Denmark, 2004.

33. Chen, F.; Balieu, R.; Kringos, N. Potential Influences on Long-Term Service Performance of Road Infrastructure by Automated Vehicles. Transp. Res. Rec. 2016, 2550, 72-79. [CrossRef]

34. Jones, P.T.; Onar, O. Impact of Wireless Power Transfer in transportation: Future transportation enabler, or near term distraction. In Proceedings of the 2014 IEEE International Electric Vehicle Conference (IEVC), Florence, Italy, 17-19 December 2014; pp. 1-7. [CrossRef]

35. Fabric. Feasibility Analysis and Development of on-road Charging Solutions for Future Electric Vehicles. Grant No. 605405. Available online: https://www.fabric-project.eu (accessed on 30 July 2019).

36. Suh, N.P. Design of wireless electric power transfer technology: Shaped magnetic field in resonance (SMFIR). In Proceedings of the 21st Cirp Design Conference, Daejeon, Korea, 28 March 2011.

37. Bi, Z.; Kan, T.; Mi, C.C.; Zhang, Y.; Zhao, Z.; Keoleian, G.A. A review of wireless power transfer for electric vehicles: Prospects to enhance sustainable mobility. Appl. Energy 2016, 179, 413-425. [CrossRef]

38. Ruffo, R.; Khalilian, M.; Cirimele, V.; Guglielmi, P.; Cesano, M. Theoretical and experimental comparison of two interoperable dynamic wireless power transfer systems for electric vehicles. In Proceedings of the 2017 IEEE Southern Power Electronics Conference SPEC, Puerto Varas, Chile, 4-7 December 2017; pp. 1-6.

39. Rosu, S.G.; Khalilian, M.; Cirimele, V.; Guglielmi, P. A dynamic wireless charging system for electric vehicles based on DC/AC converters with SiC MOSFET-IGBT switches and resonant gate-drive. In Proceedings of the IECON 2016-42nd Annual Conference of the IEEE Industrial Electronics Society, Florence, Italy, 23-26 October 2016; pp. 4465-4470. [CrossRef]

40. Khalilian, M.; Guglielmi, P. Primary-Side Control of a Wireless Power Transfer System with Double-Sided LCC Compensation Topology for Electric Vehicle Battery Charging. In Proceedings of the 2018 IEEE International Telecommunications Energy Conference (INTELEC), Turin, Italy, 7-11 October 2018; pp. 1-6. [CrossRef]

41. Ruffo, R.; Cirimele, V.; Diana, M.; Khalilian, M.; Ganga, A.L.; Guglielmi, P. Sensorless Control of the Charging Process of a Dynamic Inductive Power Transfer System with an Interleaved Nine-Phase Boost Converter. IEEE Trans. Ind. Electron. 2018, 65, 7630-7639. [CrossRef]

42. Bateman, D.; Carswell, I.; Vermaat, P.; Emre, M. Deliverable 53.2 Technical Specifications of Construction of E-Roads. 2016. Available online: https://www.fabric-project.eu (accessed on 31 July 2019).

43. Santero, N.; Masanet, E.; Horvath, A. Life-cycle assessment of pavements. Part I: Critical review. Resour. Conserv. Recycl. 2011, 55, 801-809. [CrossRef]

44. Santero, N.; Masanet, E.; Horvath, A. Life-cycle assessment of pavements Part II: Filling the research gaps. Resour. Conserv. Recycl. 2011, 55, 810-818. [CrossRef]

45. Stripple, H. Life cycle assessment of road. In A Pilot Study for Inventory Analysis, 2nd ed.; The IVL Swedish Environmental Research Institute: Stockholm, Sweden, 2001. 
46. Ceravolo, R.; Miraglia, G.; Pinotti, E.; Surace, C.; Zanotti Fragonara, L. Modelling of a road infrastructure adapted for dynamic inductive recharging for maintenance and monitoring. In Proceedings of the 7th International Conference on Structural Health Monitoring on Intelligent Infrastructures, Turin, Italy, 1-3 July 2015.

47. Ceravolo, R.; Miraglia, G.; Surace, C. Strategy for the maintenance and monitoring of electric road infrastructures based on recursive lifetime prediction. J. Civ. Struct. Health Monit. 2017, 7, 303-314. [CrossRef]

48. Miliutenko, S. Life Cycle Impacts of Road Infrastructure: Assessment of Energy Use and Greenhouse Gas Emissions; KTH Royal Institute of Technology: Stockholm, Sweden, 2012.

49. Frischknecht, R.; Wyss, F.; Knöpfel, S.B.; Lützkendorf, T.; Balouktsi, M. Cumulative energy demand in LCA: The energy harvested approach. Int. J. Life Cycle Assess. 2015, 20, 957-969. [CrossRef]

50. Guinée, J. Handbook on Life Cycle Assessment: Operational Guide to the ISO Standards; Springer Science \& Business Media: Berlin, Germany, 2002.

51. Butt, A.A. Life Cycle Assessment of Asphalt Roads. Ph.D. Thesis, KTH Royal Institute of Technology, Stockholm, Sweden, 2014.

52. Giani, M.I. Valutazione Della Sostenibilità Della Pratica di Riciclo a Freddo in-Situ di Pavimentazioni Stradali in Conglomerato Bituminoso. Master's Thesis, Politecnico di Milano, Milano, Italy, 2012.

53. EAPA. The Use of Warm Mix Asphalt-EAPA Position Paper; EAPA: Arlington County, WV, USA, 2010.

54. KTH; QiE; POLITO. FABRIC Deliverable 53.1 Integrated LCA/LCC system for evaluation of E-roads. 2016. Available online: https://www.fabric-project.eu (accessed on 31 July 2019).

55. TRL; KTH; POLITO; Vedecom. FABRIC Deliverable 45.2 Technical Specifications and Design of Solutions for Road Adaptation. 2017. Available online: https://www.fabric-project.eu (accessed on 31 July 2019).

56. Chen, F.; Coronado, C.F.; Balieu, R.; Kringos, N. Structural performance of electrified roads: A computational analysis. J. Clean. Prod. 2018, 195, 1338-1349. [CrossRef]

57. Ceravolo, R.; Miraglia, G.; Surace, C.; Zanotti Fragonara, L. A Computational Methodology for Assessing the Time-Dependent Structural Performance of Electric Road Infrastructures. Comput. Civ. Infrastruct. Eng. 2016, 31, 701-716. [CrossRef]

58. Ceravolo, R.; Miraglia, G.; Surace, C. Fatigue damage assessment of electric roads based on probabilistic load models. J. Phys. Conf. Ser. 2017, 842, 12037. [CrossRef] 